\title{
Lotus Root Sign in the Renal Artery in Renovascular Hypertension
}

\author{
Kazuhiko Nakazato, MD; Atsushi Kobayashi, MD; Minoru Nodera, MD; \\ Masashi Kamioka, MD; Hitoshi Suzuki, MD; \\ Shu-ichi Saitoh, MD; Yasuchika Takeishi, MD
}
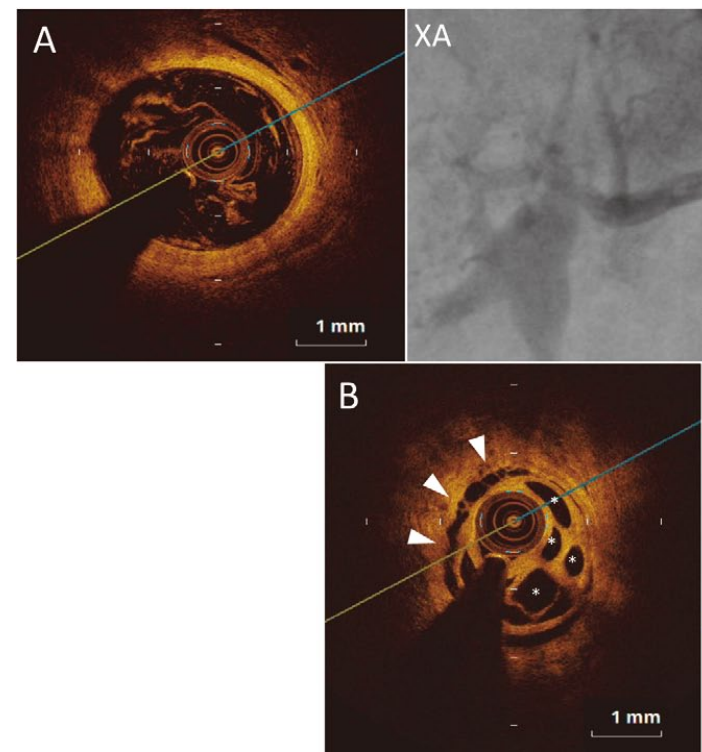

Figure 1. Angiography and cross-sectional optical coherence tomography of the right renal artery. (XA) Angiography showed moderate stenosis with (B-D) haziness and subtotal occlusion (arrow). Dissections between the intima and media (arrowheads) and lotus root sign (asterisks) were observed.

\section{A} 25-year-old man was referred due to refractory systemic hypertension despite treatment with calcium channel and angiotensin II receptor blockers. Both plasma renin activity $(69 \mathrm{ng} / \mathrm{mL} / \mathrm{h})$ and aldosterone concentration $(472 \mathrm{pg} / \mathrm{mL})$ were elevated, and renogram showed that the right kidney function was impaired. Computed tomography of the adrenal glands was normal. Abdominal arteriography was performed due to suspected renovascular hypertension. Angiography indicated diffuse stenosis and subtotal occlusion of the branch in the right renal artery (Figure 1XA). Thus, percutaneous transluminal renal angioplasty (PTRA) was performed to release the renal artery stenosis. Optical coherence tomography (OCT) was very interesting (Figure 1A-D). Although the arterial structure in the distal portion of the right renal artery was normal (Figure 1A), a lotus root-like sign was noted in the stenotic lesion (Figure 1B; asterisks). Furthermore, dissections between the intima and media were observed in the same lesion (Figure 1B; arrowheads) as well as in the area where the lotus root sign was not detected (Figure 1C; arrowheads). Dissection between the intima and media of the arterial wall has been noted with regard to fibromuscular dysplasia (FMD). ${ }^{1}$ In contrast, lotus root sign has been considered to represent vascular recanalization in the chronic phase of thrombotic occlusion. ${ }^{2}$ Figure 2 shows angiography and OCT after PTRA (Figure 2A-D corresponds to Figure 1A-D). Balloon expansion made cracks in the partitioned structure, resulting in enlargement of the vessel lumen (Figure 2B,D; arrowheads). The blood flow of the right kidney was improved after PTRA (Figure 2XA),

Received January 27, 2017; accepted February 3, 2017; released online February 28, 2017 Time for primary review: 7 days

Department of Cardiovascular Medicine, Fukushima Medical University, Fukushima, Japan

Mailing address: Kazuhiko Nakazato, MD, Department of Cardiovascular Medicine, Fukushima Medical University, Fukushima 960-1295, Japan. E-mail: nakazato@fmu.ac.jp

ISSN-1346-9843 All rights are reserved to the Japanese Circulation Society. For permissions, please e-mail: cj@j-circ.or.jp 

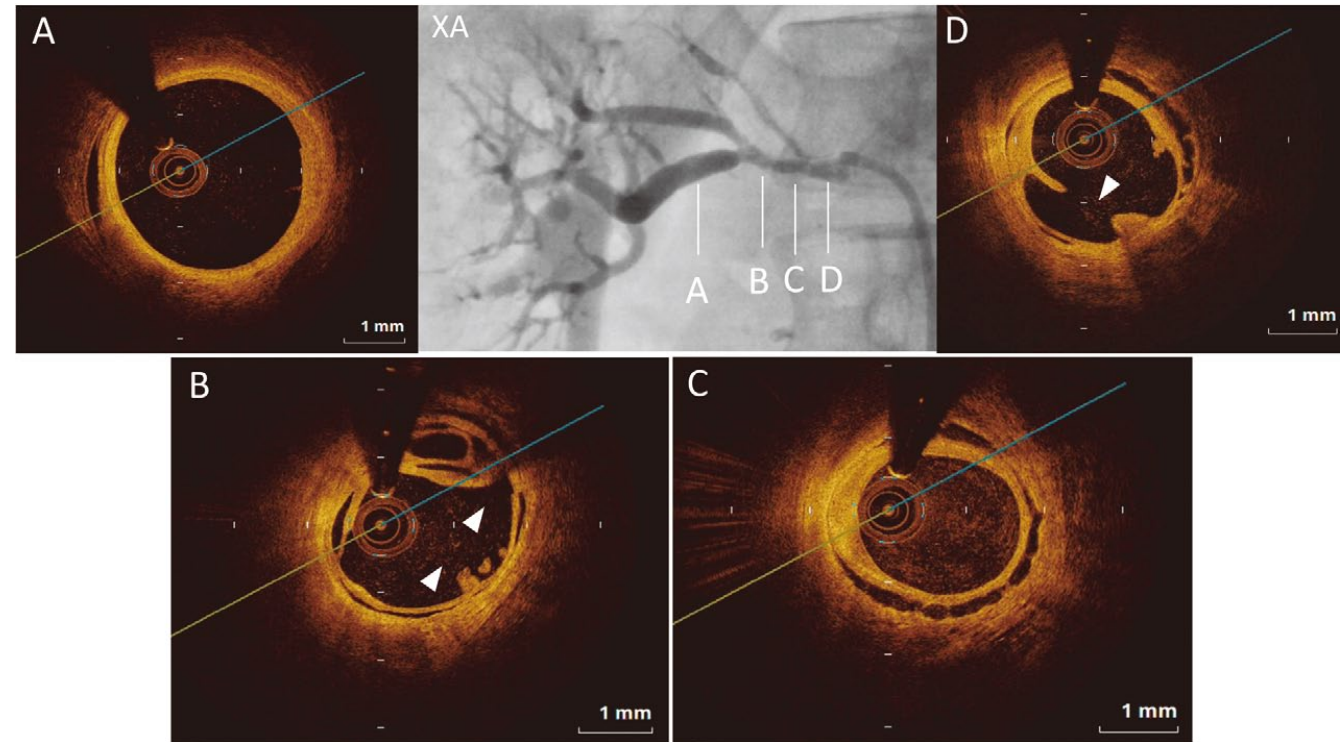

Figure 2. Angiography and optical coherence tomography after percutaneous transluminal renal angioplasty (A-D). Balloon expansion made cracks in the partitioned structure, resulting in enlargement of the vessel lumen (arrowheads).

and blood pressure was able to be controlled. This case was diagnosed as FMD for the following reasons: (1) typical atherosclerotic plaques were not observed; (2) the patient was young; and (3) dissections between the intima and media were observed on OCT. The "string of beads" sign, however, which is a typical finding of FMD, was not seen on angiography. Instead, unusually, a lotus root-like sign was observed. Lotus root sign has previously been reported in coronary artery disease, carotid artery stenosis, and chronic thromboembolic pulmonary hypertension. ${ }^{2-4}$ Reports in renovascular hypertension, however, are extremely rare. Although "a web lesion" has been reported in renal arteries in FMD on intravascular ultrasound, ${ }^{5}$ the present case report is the first to show precise OCT, and changes in the partitioned structure on balloon dilatation in a patient with renovascular hypertension.

\section{Disclosures}

The authors declare no conflict of interest.

\section{References}

1. Sanchez-Recalde A, Moreno R, Jimenez-Valero S. Renal artery fibromuscular dysplasia: In vivo optical coherence tomography insights. Eur Heart J 2014; 35: 931.

2. Kato M, Dote K, Sasaki S. Recanalized image of thrombotic occlusion with coronary plaque rupture: A lotus root-like appearance by optical coherence tomography. Can J Cardiol 2011; 27: 871.e1-e2.

3. Chang H, Yoon HJ, Hong JH, Kim CH, Sohn SI, Lee CY. A lotus root-like appearance in carotid stenosis on optical coherence tomography. BMJ Case Rep, doi:10.1136/bcr-2015011685 .

4. Tatebe S, Fukumoto Y, Sugimura K, Miura Y, Nochioka K, Aoki T, et al. Optical coherence tomography is superior to intravascular ultrasound for diagnosis of distal-type chronic thromboembolic pulmonary hypertension. Circ J 2013; 77: 10811083.

5. Fujihara M, Fukata M, Higashimori A, Nakamura H, Odashiro $\mathrm{K}$, Yokoi Y. Short- and mid-term results of balloon angioplasty for renal artery fibromuscular dysplasia. Cardiovasc Interv Ther 2014; 29: 293-299. 